\title{
Argamassas com incorporação de Materiais de Mudança de Fase (PCM): Caracterização física, mecânica e durabilidade
}

\author{
Mortars with incorporation of Phase Change \\ Materials (PCM): Physical and mechanical \\ properties and durability
}

\author{
Sandra Cunha ${ }^{1}$, José Aguiar ${ }^{1}$, \\ Victor Ferreira $^{2}$, António Tadeu ${ }^{3}$
}

\author{
${ }^{1}$ Universidade do Minho, Campus de Azurém, 4800-058 Guimarães, Portugal \\ e-mail: sandracunha86@gmail.com; aguiar@civil.uminho.pt \\ ${ }^{2}$ Universidade de Aveiro, Campus Universitário de Santiago, 3810-193 Aveiro, Portugal \\ e-mail: victorf@ua.pt \\ ${ }^{3}$ Universidade de Coimbra, Rua Luís Reis Santos - Pólo II da Universidade, 3030-788 Coimbra, Portugal \\ e-mail: tadeu@dec.uc.pt
}

\section{RESUMO}

O despertar da consciência ambiental pela sociedade, tem levantado problemas até então ignorados tais como os consumos energéticos. Numa sociedade com um elevado ritmo de crescimento e padrões de conforto cada vez maiores, surge a necessidade de minimizar os elevados consumos energéticos, tirando partido de fontes de energia renováveis. As argamassas com incorporação de materiais de mudança de fase (PCM) possuem a capacidade de regular a temperatura no interior dos edifícios, contribuindo desta forma para o aumento do nível de conforto térmico e diminuição do recurso a equipamentos de climatização, apenas com recurso à energia solar. Contudo, a incorporação de materiais de mudança de fase em argamassas modifica algumas das suas principais características. Portanto, o principal objetivo deste estudo consistiu na caracterização física e mecânica de argamassas aditivadas com PCM, assim como na avaliação da sua durabilidade. Para tal foram desenvolvidas 12 composições distintas, à base de diferentes ligantes e dopadas com 40\% de PCM. Tendo sido possível observar que a incorporação de PCM provoca diferenças significativas em propriedades tais como a trabalhabilidade, resistência à compressão, resistência à flexão, aderência, absorção de água por capilaridade, absorção de água por imersão e resistência a ações de gelo-degelo. Contudo, foi possível concluir que a incorporação de PCM nas argamassas pode ser realizada com sucesso. Sendo que, as alterações verificadas nas argamassas podem ser contornadas através da incorporação de uma maior dosagem de ligante, superplastificante e até mesmo a inclusão de fibras. Apesar dos resultados desta investigação serem promissores é importante referir que outras investigações devem ser realizadas com o intuito de observar a influência do PCM em argamassas constituídas por outros materiais.

Palavras-chave: Argamassas, material de mudança de fase, trabalhabilidade, comportamento mecânico, durabilidade.

\footnotetext{
ABSTRACT

The awakening of environmental awareness by society has raised issues previously ignored such as energy consumption. In a society with a high growth rate and increased standards of comfort arises the need to minimize the currently high energy consumption by taking advantage of renewable energy sources. The mortars with incorporation of phase change materials (PCM) have the ability to regulate the temperature inside buildings, contributing to the thermal comfort and reduction of the use of heating and cooling equipment, using only the energy supplied by the sun. However, the incorporation of phase change materials in mortars modifies its characteristics. The main purpose of this study was the physical and mechanical characterization, as well the evaluation of the durability. Twelve compositions were developed, based in different binders and doped with $40 \%$ of PCM. It was possible to observe that the incorporation of PCM in mortars caused significant differences in properties, such as workability, compression strength, flexural strength, adhesion, water absorption by capillarity, water absorption by immersion and degradation after freeze-thaw cycles. However,
} 
it was concluded that the incorporation of PCM in mortars can be performed successfully. Being that the changes in mortars can be solved by incorporating a higher content of binder, superplasticizer and the inclusion of fibers. Although the results of this investigation are promising it is important to note that further investigations should be performed aiming to observe the influence of PCM in mortars composed by other materials.

Keywords: Mortars, phase change materials, workability, mechanical behavior, durability.

\section{INTRODUÇÃO}

Todos os anos, uma energia de cerca de $5 \times 10^{24} \mathrm{~J}$ é fornecida pelo sol e atinge toda a superfície terrestre. Esta quantidade é cerca de 10000 vezes superior ao consumo real de energia por ano em todo o mundo. Assim, a necessidade de encontrar uma forma de tirar proveito deste recurso, juntamente com a procura de uma melhoria na qualidade do meio ambiente, é enorme. Isto tem conduzido os esforços da comunidade científica em combinar o uso de energia solar e materiais de construção funcionais, que permitam limitar o consumo de energia [1].

Atualmente, o elevado ritmo de crescimento das áreas urbanas e o aumento dos parâmetros de conforto, têm vindo a provocar um acréscimo nos consumos energéticos, tornando-se numa das maiores preocupações da sociedade atual. Este problema deve-se ao uso excessivo de energia proveniente de fontes não renováveis, que provocam graves impactos no meio ambiente. Sabendo-se que grande parte do consumo de energia elétrica no setor residencial está associado ao aquecimento e arrefecimento, torna-se urgente a implementação de soluções construtivas que visem aumentar a eficiência energética dos edifícios.

A capacidade de diminuir e deslocalizar os consumos energéticos, associada à utilização de materiais de mudança de fase (PCM), potenciam a sua utilização em argamassas como uma solução para a melhoria da eficiência energética dos edifícios. Desta forma, a incorporação de materiais de mudança de fase em sistemas construtivos possui benefícios sociais, económicos e ambientais, possibilitando um contributo significativo nas diferentes dimensões do desenvolvimento sustentável.

Aliando a baixa espessura conseguida com a utilização de materiais de mudança de fase a soluções de construção flexíveis é possível obter soluções com maior capacidade de adaptação ao tempo de vida das construções, caminhando no sentido de uma construção mais sustentável.

Numa sociedade que cada vez se preocupa mais com a sustentabilidade e boas práticas de construção, a durabilidade adquire cada vez mais um papel importante. A durabilidade dos materiais não é uma característica intrínseca, mas sim uma característica relacionada com o desempenho do material ao longo da sua vida útil, estando este sujeito a determinadas condições ambientais. Desta forma, não é possível generalizar o conceito de durabilidade, uma vez que este deve ser especificado tendo em conta o ambiente onde este vai ser aplicado [2].

A durabilidade dos materiais de construção encontra-se diretamente relacionada com a sustentabilidade dos mesmos. Uma vez que materiais mais duráveis conduzem a menores ações de reabilitação, o que consequentemente origina menores consumos de matérias-primas, energia e produção de resíduos. Durabilidade de um material, por definição, é a capacidade de suportar o desgaste ou deterioração. Até recentemente, existia uma suposição errada de que um material mais resistente, seria por consequência um material mais durável. Portanto, os desenvolvimentos tecnológicos dos materiais de construção concentraram-se em obter cada vez materiais mais resistentes.

O principal objetivo deste trabalho, consiste no desenvolvimento e caracterização de argamassas com incorporação de PCM. Foram desenvolvidas 12 composições distintas, com base em diferentes ligantes, de forma a poder observar a influência da adição destes materiais em vários tipos de argamassas. As argamassas desenvolvidas foram testadas quanto às suas características físicas e mecânicas, assim como a avaliação da sua durabilidade.

A avaliação das características físicas e mecânicas foi realizada segundo os ensaios de trabalhabilidade, resistência à flexão, resistência à compressão e aderência.

A durabilidade das argamassas desenvolvidas foi avaliada tendo em conta três ensaios típicos, sendo estes ensaios de gelo/degelo, absorção de água por capilaridade e porosidade.

Apesar dos vários estudos realizados com materiais de mudança de fase e da importância do conhecimento da influência da adição destes materiais em argamassas com base em diferentes ligantes assim como da sua durabilidade, estas são ainda áreas com necessidades de estudo urgentes. 


\section{A SUSTENTABILIDADE NA CONSTRUÇÃO}

Atualmente, a procura de uma construção com maior valor de sustentabilidade tem sido uma das premissas da comunidade científica e da indústria da construção. Esta procura passa por fazer uma gestão cuidada dos recursos naturais a utilizar e também pelo desenvolvimento de materiais funcionais que permitam suprimir alguns dos problemas do património edificado.

A criação de uma forte ligação entre a indústria da construção e os pilares do desenvolvimento sustentável, é particularmente importante, e desde cedo começou a merecer a atenção dos intervenientes do setor da construção. Portanto, a crescente preocupação pública e regulamentação ambiental, levou os técnicos da construção a caminhar no sentido de obter uma construção mais sustentável. Desta forma, cada vez mais é urgente considerar os impactos associados ao ambiente construído e à construção de edifícios, de forma a encontrarem-se medidas que permitam minimizar esses impactos e, se possível, eliminá-los.

\subsection{Contribuição dos Materiais de Mudança de Fase}

A incorporação de materiais de mudança de fase em edifícios possui impactos benéficos nas dimensões social, económica e ambiental, demonstrando um contributo significativo para uma construção com maior valor de sustentabilidade.

Os benefícios sociais estão diretamente relacionados com o aumento do conforto térmico no interior das habitações, sendo este um requisito relevante para a obtenção de um edifício de qualidade. $\mathrm{O}$ aumento do conforto térmico é conseguido através da capacidade de armazenamento do PCM, permitindo armazenar e libertar energia, mantendo as temperaturas interiores sensivelmente constantes, ou pelo menos com variações inferiores. A utilização de soluções construtivas modificadas com a incorporação de PCM possui ainda um efeito benéfico na humidade interior dos espaços, o que sem dúvida conduzirá a uma diminuição de eventuais patologias no interior dos edifícios.

O aspeto ambiental encontra-se relacionado com a redução do recurso a fontes de energia não renováveis, uma vez que esta tecnologia possui um efeito termo-regulador do ambiente interior dos edifícios, proporcionando uma diminuição da utilização dos equipamentos de climatização, que também permite reduzir as emissões de gases poluentes para a atmosfera.

A dimensão económica diz respeito à adequação da tecnologia e custos associados à sua implementação. Os custos inerentes à sua aplicação devem ser facilmente suportados e amortizados pelo utilizador. Pode ainda referir-se que, os benefícios económicos da diminuição dos consumos energéticos e desfasamento dos mesmos para fora das horas de maior procura, são evidentes e podem ser conseguidos através do armazenamento térmico.

A amortização e rentabilidade de uma solução com incorporação de PCM, é fortemente influenciada pelo preço do PCM e deve ser estudada antes da aplicação da tecnologia construtiva. No entanto, o aumento do preço da energia praticado nos últimos anos e a forte dependência de Portugal em termos energéticos, devem ser fatores a ponderar na estimativa de rentabilidade deste tipo de solução.

A eficiência energética dos edifícios é hoje um dos principais objetivos da política energética a nível internacional [3]. Os edifícios são um dos setores líderes no consumo de energia nos países desenvolvidos, sendo que na União Europeia são responsáveis por cerca de $40 \%$ do consumo de energia e pela produção de cerca de $40 \%$ das emissões de $\mathrm{CO}_{2}$ para a atmosfera.

Numa abordagem sustentável, os edifícios devem ser projetados para garantir o conforto térmico dos ocupantes durante todo o ano, com um mínimo de energia auxiliar para aquecimento e arrefecimento. Em abordagens não-sustentáveis, os edifícios são cada vez mais dependentes de sistemas de climatização que permitam garantir o conforto térmico no seu interior. Este tipo de medida origina um aumento no consumo de energia, bem como um aumento das emissões de gases de efeito de estufa. Consequentemente, verifica-se também um aumento dos custos de utilização do edifício, uma vez que o preço dos combustíveis fosseis têm um grande impacto nos custos de operação dos sistemas de climatização, conduzindo-nos a um aumento do custo operacional dos edifícios durante todo o seu ciclo de vida [ $\underline{3}, \underline{4}]$.

O recurso a aplicações relacionadas com a utilização de energias renováveis contribui para o aumento da eficiência energética, diminuição do recurso a reservas de combustíveis fósseis e consequente diminuição das emissões de poluentes para a atmosfera, tornando-se numa medida de atuação crucial na promoção da eficiência energética e da sustentabilidade dos edifícios. Além disso, a utilização de fontes de energia renováveis é um fator decisivo na redução da dependência energética dos edifícios. Portanto, o recurso ao arma- 
zenamento térmico através da utilização de materiais de mudança de fase constitui uma estratégia para o desenvolvimento de projetos construtivos com elevado desempenho energético.

\section{MATERIAIS DE MUDANÇA DE FASE}

É do conhecimento geral que todos os materiais interagem com o ambiente, no entanto, grande parte não possui capacidade de alterar as suas propriedades de acordo com as características do ambiente em que são aplicados.

Os materiais de mudança de fase, denominados na língua inglesa de "Phase Change Materials" (PCM), possuem a capacidade de mudar o seu estado em função da temperatura ambiente. Quando a temperatura ambiente que rodeia o PCM aumenta e passa o ponto de fusão do material, este passa de estado sólido para estado líquido, absorvendo e armazenando a energia calorífica ambiente. Quando a temperatura ambiente baixa, e passa o ponto de solidificação do PCM, então este passa do estado liquido para o estado sólido, libertando a energia anteriormente armazenada.

Para a correta utilização do PCM, este deve ser encapsulado, caso contrário, durante a fase líquida pode correr-se o risco deste se deslocar do local em que foi aplicado. Existem duas principais formas de encapsulamento: microencapsulamento e macroencapsulamento [5]. O macroencapsulamento baseia-se na introdução de PCM em tubos, painéis ou outro recipiente de grandes dimensões, geralmente é efetuado em recipientes com mais de $1 \mathrm{~cm}$ de diâmetro [5]. O microencapsulamento de PCM consiste na colocação de uma pequena massa molecular em pequenas partículas, revestidas por polímeros de alto desempenho. As microcápsulas podem ser esféricas ou assimétricas e com forma variável, com diâmetro inferior a $1 \mathrm{~cm}$, contudo o diâmetro preferencial situa-se entre os $1-60 \mu \mathrm{m}$. A vantagem deste processo de encapsulamento é a melhoria da transferência de calor, através da sua grande superfície [-ㅡㄹ.

Nem todos os PCM existentes podem ser utilizados para o armazenamento térmico. Os materiais de mudança de fase devem possuir um ponto de fusão/solidificação na gama de temperaturas da sua aplicação prática, assim como um elevado calor latente de fusão e condutibilidade térmica.

Um PCM ideal deve possuir algumas propriedades termofísicas, cinéticas, químicas, ambientais e económicas desejáveis $[\underline{8}, 9]$. Relativamente às propriedades termofísicas é necessário que o PCM selecionado possua uma temperatura de transição na gama de temperaturas de operação desejadas, com o intuito de garantir o armazenamento e a libertação de calor. Assim como elevado calor de transição por unidade de volume, de modo a armazenar o máximo de energia possível incorporando a quantidade mínima de PCM; elevado calor sensível, traduzido pela sua capacidade calorífica, de modo a aumentar a sua capacidade de armazenamento de energia; elevada condutibilidade térmica tanto no estado sólido como no estado líquido, de forma a mais facilmente promover a transferência de calor e reduzida variação de volume durante a transição de fase, de forma a reduzir os problemas relacionados com a sua contenção [ $\underline{5}, \underline{8}]$, assim como elevada densidade, fusão congruente e estabilidade térmica a longo prazo, baixa variação de volume e ausência de segregação durante a mudança de fase [9]. Do ponto de vista cinético, o PCM escolhido deve ter uma elevada velocidade de crescimento dos cristais, com o objetivo de evitar o sub-arrefecimento da fase líquida e responder às solicitações do meio envolvente [ $[\underline{6}, \underline{8}]$. No que diz respeito às suas propriedades químicas não deverá apresentar degradação após um grande número de ciclos, deverá ser não corrosivo para os materiais de construção, não inflamável, não tóxico e não explosivo, por razões ambientais e de segurança [ $[\underline{5}, \underline{8}]$. No que confere às suas propriedades ambientais os materiais de mudança de fase devem apresentar baixo consumo de energia incorporada, facilidade de separação de outros materiais, elevado potencial de reciclagem e baixo impacto ambiental [9]. Finalmente, sob o ponto de vista económico este deve ser abundante, disponível e com baixo custo de aquisição, de forma a se tornar uma solução competitiva com outros sistemas construtivos [ $\underline{5}, \underline{8}]$.

\subsection{Os Materiais de Mudança de Fase na Construção}

De todas as aplicações de PCM em edifícios, a mais interessante é a sua incorporação em materiais de construção com o objetivo de alterar as suas propriedades térmicas. Existem uma série de possibilidades: o PCM pode ser usado como um meio de armazenamento térmico para aquecimento solar passivo, pode ser incorporado no pavimento, na parede ou no teto e pode também fazer parte do mais complexo sistema térmico, tais como bombas de calor e painéis solares, sendo que a grande vantagem da incorporação de PCM nos edifícios é a vasta área que estes oferecem para armazenamento e transferência de calor.

A aplicação de PCM nas paredes dos edifícios constitui a solução preferencial para a exploração das potencialidades destes materiais. A incorporação de materiais de mudança de fase em placas de gesso tem 
vindo a ser objeto de diversos estudos realizados, devido ao seu baixo custo e variedade de aplicação. No entanto, os princípios de armazenamento de calor latente, podem ser aplicados a diversos materiais de construção [10].

Vários têm sido os autores que estudaram a incorporação de materiais de mudança de fase em placas de gesso cartonadas. ATHENITIS et al. [11], realizaram uma campanha experimental e numérica, com materiais de mudança de fase incorporados em placas de gesso, aplicadas nas paredes de um edifício. Demonstrando, uma diminuição da temperatura ambiente máxima em cerca de $4^{\circ} \mathrm{C}$. SHILEI et al. [12], também efetuaram estudos com PCM incorporado em placas de gesso, com $9.5 \mathrm{~mm}$ de espessura e $26 \%$ de PCM, com temperatura de transição de $17,9^{\circ} \mathrm{C}$ a $20,3^{\circ} \mathrm{C}$. A investigação permitiu verificar uma menor oscilação de temperatura, nas células tratadas com PCM. Assim como, ainda foi possível verificar que os ensaios de calorimetria diferencial de varrimento (DSC) são uma boa base para prever o desempenho de uma solução com incorporação de PCM à escala real.

A incorporação de PCM em elementos para a construção tais como blocos, tijolos e outros materiais convencionais, para além das placas de gesso cartonado, também foram objeto de estudo. CABEZA et al. [5] construíram e monitorizaram o comportamento de células de teste em betão, com e sem incorporação de 5\% em massa de microcápsulas de PCM. O betão com incorporação de PCM foi utilizado na cobertura e nas paredes Sul e Oeste. Durante o verão e sem ventilação, foram registados $3^{\circ} \mathrm{C}$ de diferença na temperatura superficial máxima da parede Oeste, com um desfasamento temporal de 2 horas.

Contudo, os materiais de mudança de fase também têm vindo a ser aplicados em outros materiais, tais como painéis em PVC. AHMAD et al. [13] investigaram um novo tipo de painéis em PVC alveolar com incorporação PCM. Os painéis foram utilizados na construção de uma célula de teste, em que o seu comportamento foi comparado ao de uma célula de teste de referência. Durante o período de Verão a amplitude da temperatura no interior da célula com $\mathrm{PCM}$ foi diminuída em cerca de $20^{\circ} \mathrm{C}$. No inverno, a presença do material de mudança de fase impediu que a temperatura interna negativa fosse inferior a $-6^{\circ} \mathrm{C}$, contrariando a temperatura exterior inferior a $-9^{\circ} \mathrm{C}$, demonstrando, desta forma o efeito benéfico da incorporação de PCM na regulação da temperatura no interior de edifícios.

Outras investigações foram efetuadas aplicando os materiais de mudança de fase em pavimentos, tetos e envidraçados [14-17]. ENTROP et al. [18], efetuaram uma investigação, na qual incorporaram PCM, no betão constituinte do pavimento. Para tal foram realizadas quatro células de teste totalmente isoladas, com uma janela voltada a sul através da qual a radiação solar podia entrar. Sendo possível concluir que a aplicação de PCM no pavimento originou uma redução das temperaturas máximas de cerca de $16 \%$ e um aumento das temperaturas mínimas de cerca de $7 \%$.

\section{MATERIAIS, COMPOSIÇÕES, FABRICO E PROCEDIMENTOS DE ENSAIO}

\subsection{Materiais}

A seleção dos materiais, tais como ligantes e microcápsulas de PCM teve em consideração trabalhos anteriores [19-21]. Nesta investigação foram utilizados quatro ligantes diferentes: cimento Portland CEM II B-L $32.5 \mathrm{~N}$, cal hidráulica NHL5, cal aérea e gesso.

Tendo como objetivo o conhecimento das microcápsulas de PCM foram efetuados vários ensaios para a sua caracterização. As microcápsulas são constituídas por uma parede em melamina-formaldeído, com temperatura de transição de $24^{\circ} \mathrm{C}$ e entalpia de $147.9 \mathrm{~kJ} / \mathrm{kg}$, tendo sido produzidas pela DEVAN, S. A. Através de ensaios realizados com recurso ao microscópio eletrónico de varredura (MEV) de alta resolução, foi possível observar, que o polímero presente nas microcápsulas de PCM (Figura 1) apresenta uma textura regular. Com o objetivo de obter dados mais precisos relacionados com as suas dimensões, foram realizados ensaios de granulometria, com auxílio de um granulómetro laser, sendo possível observar que possuem uma distribuição de partícula de 5.8-339 $\mu \mathrm{m}$, apresentando um tamanho médio de partícula de $43.91 \mu \mathrm{m}$ (Figura 2).

A areia utilizada apresentou um tamanho de partícula médio de 439,9 $\mu \mathrm{m}$ e uma massa volúmica real de $2600 \mathrm{~kg} / \mathrm{m}^{3}$. O superplastificante utilizado é baseado em poliacrilato, com densidade de $1050 \mathrm{~kg} / \mathrm{m}^{3}$. Por último, as fibras utilizadas são fibras sintéticas de poliamida, com um comprimento de $6 \mathrm{~mm}$ e densidade de $1380 \mathrm{~kg} / \mathrm{m}^{3}$. 


\subsection{Composições, fabrico e procedimentos de ensaio}

Foram desenvolvidas 12 formulações distintas com base nos diferentes ligantes, as quais se apresentam na Tabela 1. As formulações em estudo são constituídas por diferentes ligantes, existindo sempre uma composição de referência, ou seja sem adição de PCM, e uma composição com incorporação de $40 \%$ de PCM. Com o objetivo de suprimir alguns problemas relacionados com a retração das argamassas foram ainda desenvolvidas argamassas com incorporação de fibras de poliamida. No que diz respeito às argamassas de cal aérea foi ainda necessário desenvolver composições para dosagens mais elevadas de ligante, com o objetivo de se obter um melhor desempenho mecânico.

O processo de mistura e fabrico dos provetes para a determinação da resistência à compressão e flexão foi efetuado de acordo com norma EN 1015-11, com ligeiras adaptações devido à incorporação do PCM [22]

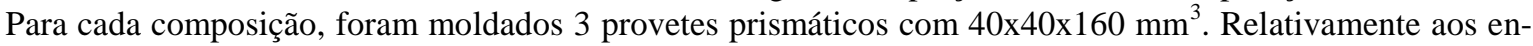
saios de determinação da aderência, o procedimento de preparação dos elementos de ensaio foi realizado em conformidade com a norma EN 1015-12 [르]. Para cada composição em estudo, foram preparados cinco provetes circulares com um diâmetro de $50 \mathrm{~mm}$.

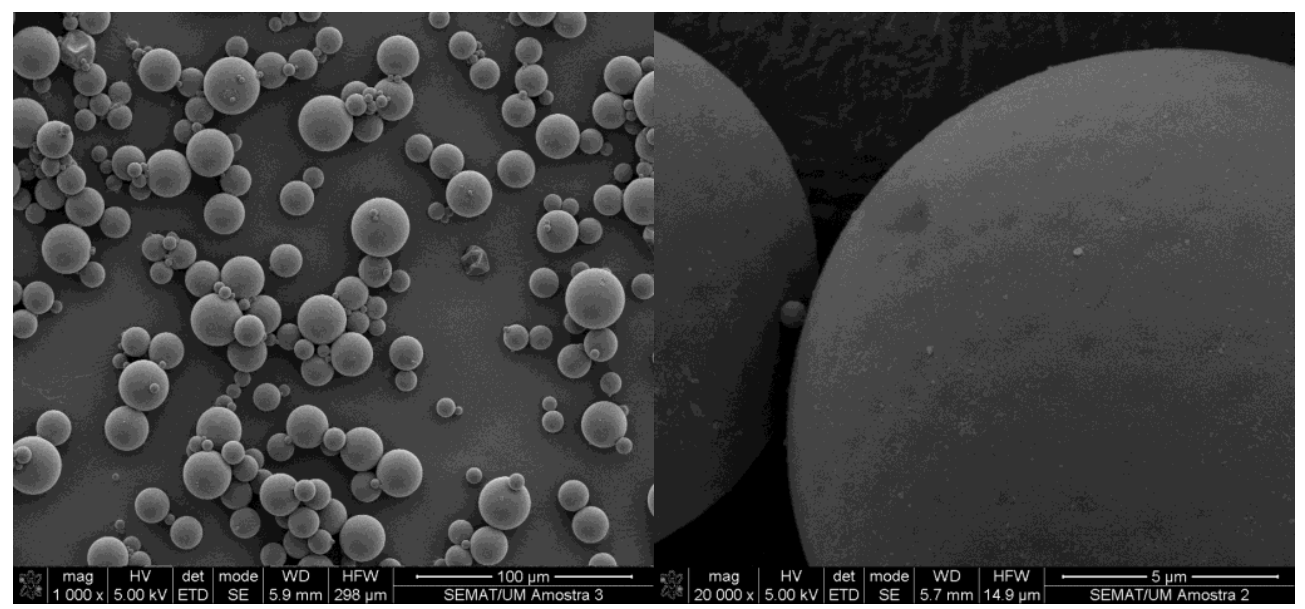

Figura 1: Observação das microcápsulas de PCM.

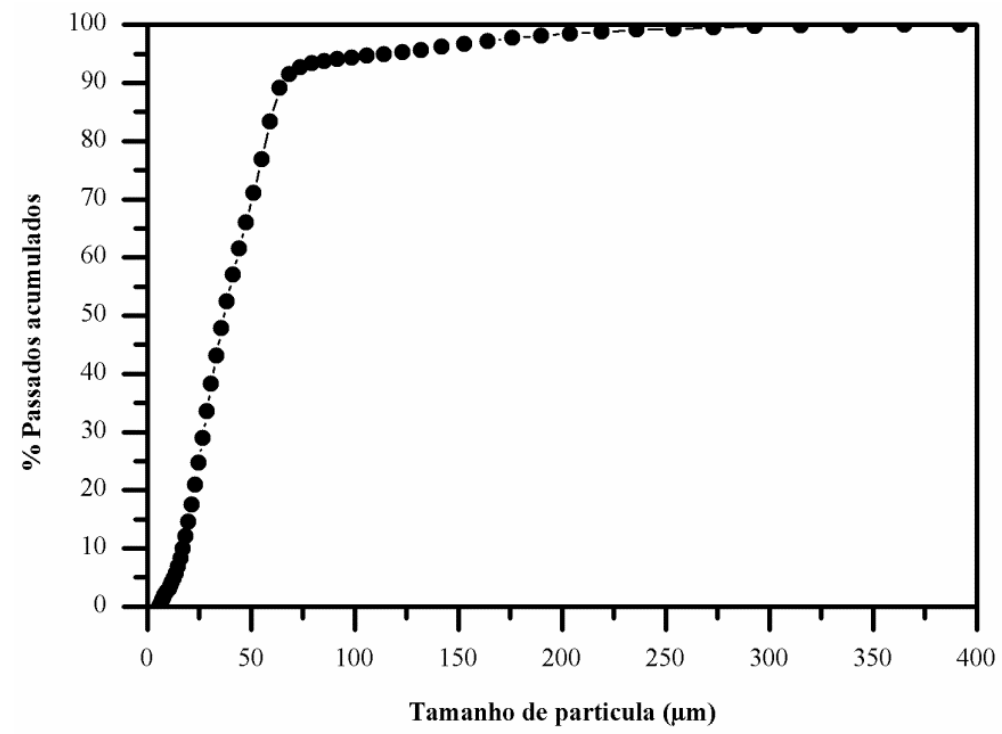

Figura 2: Granulometria das microcápsulas de material de mudança de fase.

Relativamente à avaliação da durabilidade, no que respeita ao ensaio de absorção de água por capilaridade e absorção de água por imersão foram moldados 3 provetes prismáticos para cada composição com 
40x40x160 $\mathrm{mm}^{3}$ em conformidade com a norma europeia EN 1015-18 e a especificação LNEC E 394 [24, 25]. Para a realização dos ensaios de gelo-degelo foram moldados cinco provetes cúbicos com 50x50x50 $\mathrm{mm}^{3}$, para cada composição de acordo com a especificação CEN/TS 12390-9 [26].

Após o seu fabrico, todos os provetes foram conservados durante 7 dias em sacos de polietileno, sendo posteriormente colocados em laboratório à temperatura ambiente (cerca de $22^{\circ} \mathrm{C}$ ) durante 21 dias.

Tabela 1: Formulação das argamassas $\left(\mathrm{kg} / \mathrm{m}^{3}\right)$.

\begin{tabular}{l|l|l|l|l|l|l|l}
\hline COMPOSIÇÃO & LIGANTE & AREIA & PCM & SUPERPLASTIFICANTE & FIBRAS & ÁGUA \\
\hline CA500-0PCM & Cal Aérea & 500 & 1447,2 & 0 & 15 & 0 & 225 \\
\hline CA800-40PCM & Cal Aérea & 800 & 451,2 & 180,5 & 24 & 0 & 272 \\
\hline CA800-80PCM-F & Cal Aérea & 800 & 447,7 & 179,1 & 24 & 4 & 272 \\
\hline CH500-0PCM & Cal Hidráulica & 500 & 1351,1 & 0 & 15 & 0 & 270 \\
\hline CH500-40PCM & Cal Hidráulica & 500 & 571,6 & 228,6 & 15 & 0 & 310 \\
\hline CH500-40PCM-F & Cal Hidráulica & 500 & 569,4 & 227,8 & 15 & 2,5 & 310 \\
\hline C500-0PCM & CEM II B-L 32.5N & 500 & 1418,8 & 0 & 15 & 0 & 275 \\
\hline C500-40PCM & CEM II B-L 32.5N & 500 & 644,3 & 257,7 & 15 & 0 & 280 \\
\hline C500-40PCM-F & CEM II B-L 32.5N & 500 & 642,2 & 256,9 & 15 & 2,5 & 280 \\
\hline G500-0PCM & Gesso & 500 & 1360,4 & 0 & 15 & 0 & 280 \\
\hline G500-40PCM & Gesso & 500 & 540,1 & 216,0 & 15 & 2,5 & 350 \\
\hline G500-40PCM-F & Gesso & 500 & 537,9 & 215,2 & 15 & 0 & 350 \\
\hline
\end{tabular}

A avaliação da aderência foi realizada com base na norma EN 1015-1012 [23]. O ensaio permitiu estimar a aderência das argamassas aos 28 dias de idade, quando aplicadas a um substrato cerâmico. Os ensaios de aderência apenas foram realizados para as composições de referência (0\% PCM) e para as composições com incorporação de $40 \%$ de PCM e $1 \%$ de fibras de poliamida, uma vez que as composições com incorporação de $40 \%$ de PCM e sem qualquer adição de fibras revelaram uma elevada retração, apresentado fissuras à superfície o que impossibilitou a realização destes ensaios.

A realização do ensaio para determinação da absorção de água por capilaridade foi efetuada com base na especificação EN 1015-18 [24]. Os elementos de ensaio foram obtidos por corte, atraves dos ensaios de flexão para 3 provetes prismáticos, resultando assim em 6 elementos de ensaio. Em todos os provetes optouse por colocar em contacto com a água a face resultante das operações de corte de acordo com o ensaio de flexão. Garantindo-se desta forma que a face em contacto com a água possuía os canais capilares realmente presentes na argamassa em estudo, eliminando-se desta forma o contacto da água com uma face mais rica em finos e consequentemente com menos vazos capilares. A quantificação da água absorvida foi realizada através da realização de sucessivas pesagens dos provetes. Estas pesagens foram feitas de acordo com um plano de pesagens previamente estabelecido, com início no primeiro contato dos provetes com a água. Com o objetivo de avaliar a evolução de absorção de água até à sua estabilização, foram realizadas medições periódicas durante 9 dias. As pesagens foram sempre efetuadas depois de removida a água superficial.

A determinação da absorção de água por imersão foi efetuada com base na especificação do LNEC E 394 [25]. Inicialmente os provetes foram secos em estufa até atingirem a massa contante. Posteriormente foram saturados num recipiente com água de consumo a uma temperatura de $20 \pm 3^{\circ} \mathrm{C}$, ate atingirem novamente a massa constante, ou seja uma variação de massa inferior a $0.1 \%$ em medições sucessivas intervaladas de 24 horas. Por último foi determinada a sua massa hidrostática após a saturação.

A determinação do comportamento das argamassas a ciclos gelo-degelo foi avaliada com base na especificação europeia CEN/TS 12390-9 [26]. O equipamento utilizado para a realização dos ensaios, foi programado com uma lei de temperaturas em que cada ciclo de gelo-degelo teve uma duração de $24 \mathrm{~h}$, tendo sido realizados um total de 56 ciclos. Durante cada ciclo de gelo-degelo a temperatura variou entre os $24^{\circ} \mathrm{C}$ e os $18^{\circ} \mathrm{C}$. Com o intuito de contabilizar a perda de massa de cada provete, estes foram colocados individualmente 
em recipientes capazes de conter as suas perdas de massa, resultantes da degradação sofrida durante os ensaios. A quantificação da perda de massa dos provetes sujeitos aos ciclos de temperatura foi realizada através da realização de sucessivas pesagens. Estas pesagens foram feitas de acordo com um plano de pesagens previamente estabelecido, com início no primeiro ciclo gelo-degelo. Os elementos de testes foram saturados e posteriormente submetidos aos ciclos de temperatura. Durante o ensaio cada provete foi colocado em contacto com uma lâmina de água, com o objetivo do provete absorver a água perdida por evaporação e também pela ventilação do próprio equipamento, garantindo-se desta forma que os poros dos provetes estariam sempre saturados. O equipamento foi também programado com uma humidade relativa constante de $90 \%$, de forma a evitar grandes perdas de massa por evaporação da água.

\section{RESULTADOS E DISCUSSÃO}

\subsection{Trabalhabilidade}

Os ensaios de trabalhabilidade foram realizados com o objetivo de conferir uma trabalhabilidade adequada ao manuseio das argamassas desenvolvidas, tendo sido realizados com base no método da mesa de espalhamento, especificado pela norma europeia EN 1015-3 [27]. O valor resultante do ensaio apenas foi considerado, quando compreendido entre $200-220 \mathrm{~mm}$.

De acordo com a Figura 3 foi possível verificar um aumento na quantidade de água a adicionar à argamassa com a incorporação de 40\% de microcápsulas de PCM. Sendo que a incorporação de 40\% de PCM originou um aumento na quantidade de água superior a $15 \%$ para as argamassas à base de cal hidráulica e gesso. Nas argamassas à base de cimento o aumento verificado foi de apenas $2 \%$. Este comportamento, é justificado pela finura característica das microcápsulas de PCM e também pela possível absorção da parede polimérica que as constitui. Contudo, nas argamassas à base de cal aérea verificou-se uma diminuição da quantidade de água de cerca de $24 \%$, o que é justificado pela presença de uma maior dosagem de superplastificante, uma vez que a quantidade deste é proporcional à dosagem de ligante.
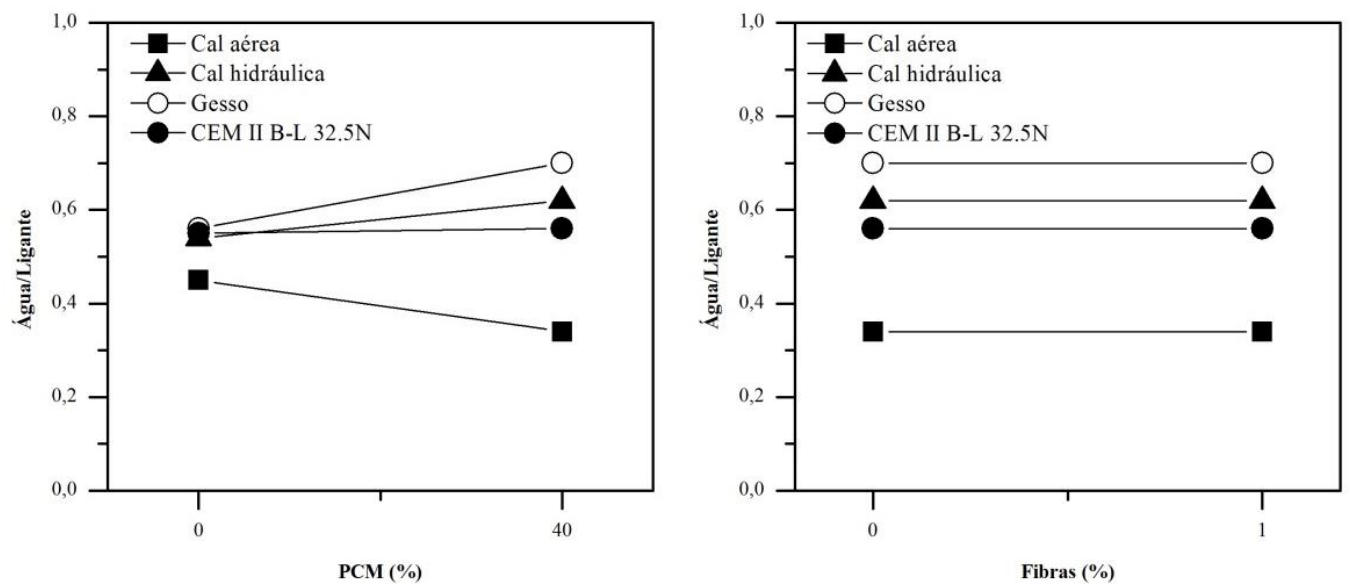

Figura 3: Relação água/ligante necessária para a obtenção de argamassas com a consistência desejada (200-220 mm).

No que diz respeito à incorporação das fibras de poliamida, foi possível verificar que a sua incorporação não provocou qualquer alteração na quantidade de água a adicionar às argamassas.

\subsection{Comportamento à flexão e à compressão}

A avaliação da resistência à flexão e compressão foi efetuada com base na norma europeia EN 1015-11 [ㄹ2], aos 28 dias de idade dos elementos de ensaio.

Para o comportamento em flexão foram utilizados provetes prismáticos com dimensões de $40 \times 40 \times 160 \mathrm{~mm}^{3}$. Os ensaios foram realizados com controlo de força, a uma velocidade de $50 \mathrm{~N} / \mathrm{s}$. O comportamento em compressão foi avaliado efetuando a aplicação da carga no provete com recurso a uma peça metálica, suficientemente rígida para uniformizar a carga vertical. Os provetes utilizados para o ensaio foram as metades resultantes dos ensaios de flexão. Os ensaios foram realizados com controlo de força, a uma veloci- 
dade de $150 \mathrm{~N} / \mathrm{s}$.

De acordo com a Figura 4, foi possível observar que a incorporação de PCM originou uma diminuição da resistência à flexão e compressão em todos os ligantes estudados. Sendo que a incorporação de $40 \%$ de microcápsulas de PCM originou uma diminuição da resistência à flexão superior a 35\%. No que diz respeito à resistência à compressão foi possível observar uma diminuição do seu valor superior a 59\%. A diminuição verificada na resistência à flexão e compressão com a incorporação de PCM, encontra-se relacionada com a presença de uma maior dosagem de água nas dopadas com este material, sendo que a evaporação da água de mistura origina maiores índices de porosidade, que por sua vez, reduzem a resistência das argamassas. Além do aumento da porosidade ainda existe o efeito do tipo de partículas, uma vez que as microcápsulas de PCM são adicionadas como substituição da areia. Assim, a diminuição da resistência à flexão e compressão também se encontra relacionada com a menor resistência mecânica das partículas de PCM quando comparadas com a resistência do agregado.

Durante o desenvolvimento deste trabalho o principal objetivo foi a obtenção de argamassas com qualidade suficiente para aplicação em rebocos interiores, pelo que foi efetuada a classificação das mesmas segundo a resistência à compressão (Tabela 2), de acordo com a norma NP EN 998-1 [28]. Assim, a premissa desta investigação foi a obtenção de argamassas aditivadas com material de mudança de fase com uma classe mínima de resistência CSII. De acordo com a Tabela 3, foi possível comprovar que todas as argamassas desenvolvidas possuem uma classe de resistência adequada para aplicação na indústria da construção. Contudo, alguns estudos iniciais, permitiram verificar que as argamassas à base de cal aérea mostravam uma classificação inferior pelo que foi realizada uma nova campanha experimental, enriquecendo as argamassas com uma dosagem superior de ligante de $800 \mathrm{~kg} / \mathrm{m}^{3}$. Assim, foi possível verificar que mesmo as argamassas sofrendo uma diminuição das suas características mecânicas estas ainda se encontram em boas condições de aplicação.

A Figura 5 apresenta o comportamento mecânico das argamassas com incorporação de fibras. No que diz respeito à resistência à flexão foi possível observar um incremento de cerca de $51 \%$ para as argamassas à base cal. Sendo que se pode considerar que as argamassas à base de cal hidráulica, gesso e cimento não apresentaram nenhuma influencia relacionada com a incorporação de fibras. Contudo, a melhoria verificada essencialmente para as argamassas à base de cal aérea encontra-se relacionada com a capacidade de oposição à formação de fendas que as fibras oferecem.

No que diz respeito à sua resistência à compressão é possível verificar um aumento significativo nas argamassas à base de cal aérea. $\mathrm{O}$ que se encontra relacionado com a capacidade que as fibras possuem em preencher alguns dos vazios na microestrutura da argamassa, diminuindo desta forma a porosidade e consequentemente aumentando a sua resistência e também pela presença de uma maior dosagem de ligante. Os restantes ligantes não exibem nenhuma influência significativa no seu comportamento à compressão.

\subsection{Aderência}

A Figura 6 apresenta os resultados obtidos durante a realização destes testes. Sendo possível verificar uma diminuição da aderência com a incorporação de material de mudança de fase. A incorporação de $40 \%$ de PCM provocou uma diminuição da aderência superior a 33\%, o que pode ser justificado pela diminuição verificada na resistência à flexão e compressão, que mais uma vez se encontra relacionado com a presença de uma maior porosidade, devido à presença de uma maior relação de água/ligante. Assim como, com o fato da aderência entre as microcápsulas de PCM e a pasta ligante ser inferior à aderência entre as partículas de areia e a pasta ligante. 

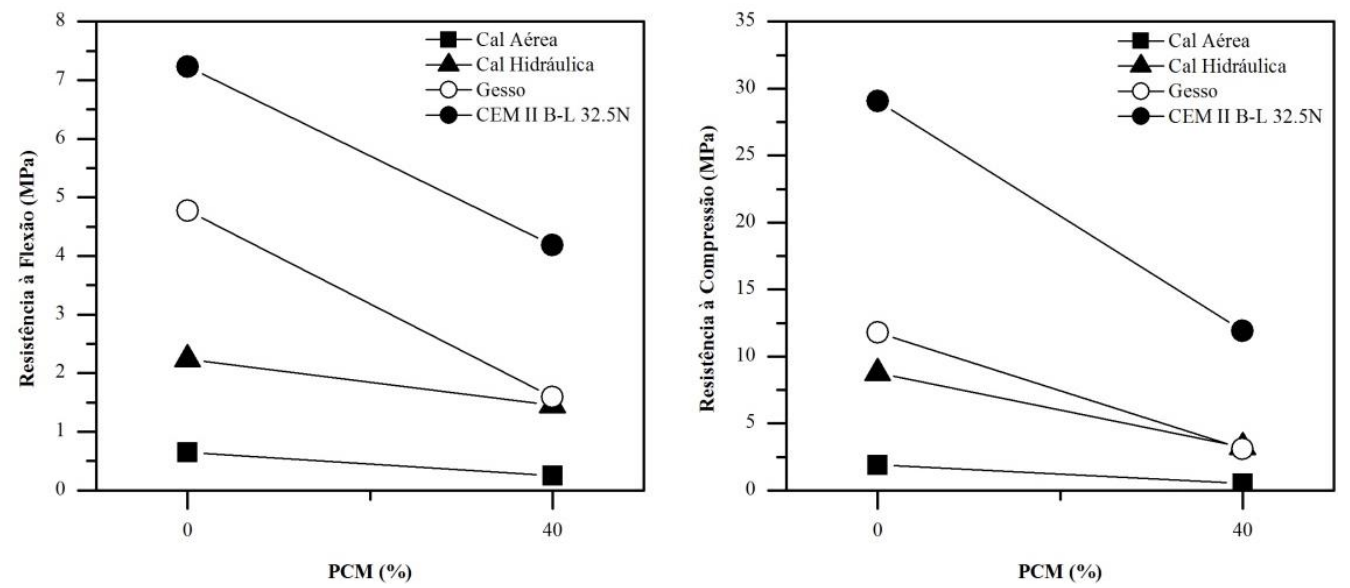

Figura 4: Comportamento à Flexão e Compressão das argamassas.

\subsection{Absorção de água por capilaridade}

A capacidade de absorção de água das argamassas possui uma grande influência na sua durabilidade, uma vez que esta característica determina a facilidade de penetração de agentes agressivos no interior das mesmas.

A Figura 7 apresenta o comportamento das argamassas estudadas durante os 9 dias de ensaios realizados. De acordo com os dados apresentados para o valor do coeficiente de absorção de água por capilaridade, é possível mais uma vez comprovar que as argamassas à base de gesso apresentam um processo de saturação mais rápido, sendo que praticamente após 150 minutos em contato com a água, os provetes se encontravam saturados. As argamassas à base de cimento apresentaram uma menor velocidade de absorção de água por capilaridade, tendendo a saturação dos elementos em ensaio apenas após os 7 dias de ensaio.

Tabela 2: Classificação das argamassas de acordo com a especificação NP EN 998-1:2010

\begin{tabular}{l|l}
\hline CLASSIFICAÇÃO & RESISTÊNCIA À COMPRESSÃO \\
\hline CSI & 0.4 to $2.5 \mathrm{MPa}$ \\
\hline CSII & 1.5 to $5.0 \mathrm{MPa}$ \\
\hline CSIII & 3.5 to $7.5 \mathrm{MPa}$ \\
\hline CSIV & $\geq 6.0 \mathrm{MPa}$ \\
\hline
\end{tabular}

Tabela 3: Classificação das argamassas segundo a resistência à compressão.

\begin{tabular}{l|l|l|l}
\hline COMPOSIÇÃO & LIGANTE & $\begin{array}{l}\text { RESISTÊNCIA À } \\
\text { COMPRESSÃO (MPa) }\end{array}$ & $\begin{array}{l}\text { CLASSIFICAÇÃO DA ARGAMASSA } \\
\text { NP EN 998-1:2010 }\end{array}$ \\
\hline CA500-0PCM & Cal Aérea & 1,90 & CSII \\
\hline CA800-40PCM & Cal Aérea & 1,53 & CSII \\
\hline CA800-80PCM-F & Cal Aérea & 3,46 & CSII \\
\hline CH500-0PCM & Cal Hidráulica & 8,76 & CSIV \\
\hline CH500-40PCM & Cal Hidráulica & 3,24 & CSII \\
\hline CH500-40PCM-F & Cal Hidráulica & 3,48 & CSII \\
\hline C500-0PCM & CEM II B-L 32.5N & 29,05 & CSIV \\
\hline C500-40PCM & CEM II B-L 32.5N & 11,91 & CSIV \\
\hline C500-40PCM-F & CEM II B-L 32.5N & 10,69 & CSIV \\
\hline G500-0PCM & Gesso & 11,78 & CSIV \\
\hline G500-40PCM & Gesso & 3.10 & CSII \\
\hline G500-40PCM-F & Gesso & 2,49 & CSII \\
\hline
\end{tabular}



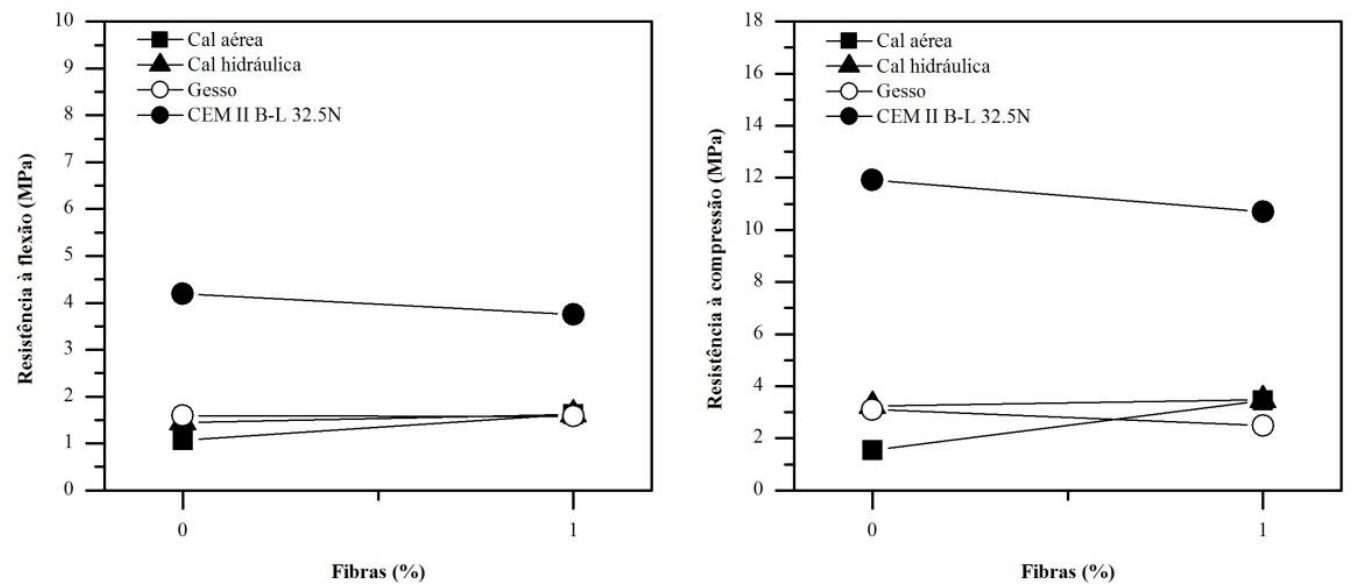

Figura 5: Comportamento à Flexão e Compressão das argamassas com incorporação de fibras.

De acordo com a Figura 8 foi possível verificar que as argamassas à base de gesso apresentam os maiores valores de coeficiente de absorção de água por capilaridade. Enquanto que, as argamassas de cimento apresentam valores significativamente mais baixos, quando comparadas com os ligantes restantes.

A incorporação de $40 \%$ de PCM causou uma diminuição no coeficiente de absorção capilar de cerca de $15 \%$ nas argamassas à base de cal hidráulica e de cerca de 33\% nas argamassas à base de cimento. Por outro lado, também foi possível observar um aumento no coeficiente de absorção capilar de cerca de $9 \%$ para as argamassas de cal aérea e de $17 \%$ nas argamassas à base de gesso.

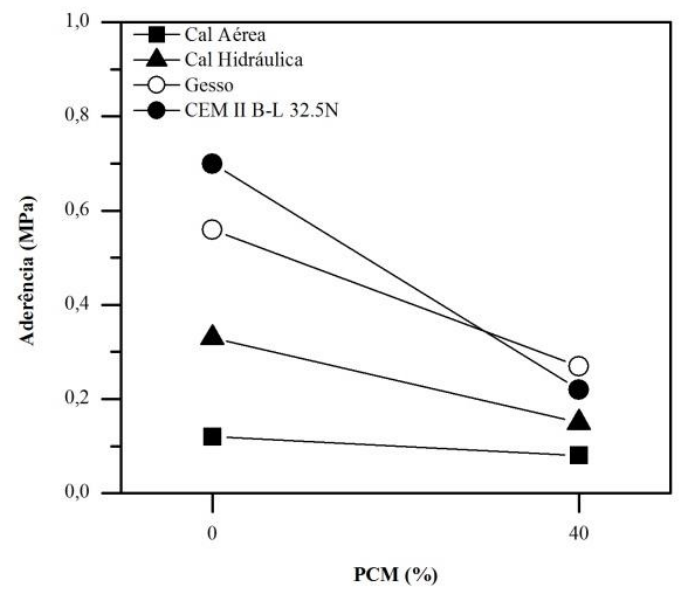

Figura 6: Aderência das argamassas desenvolvidas. 

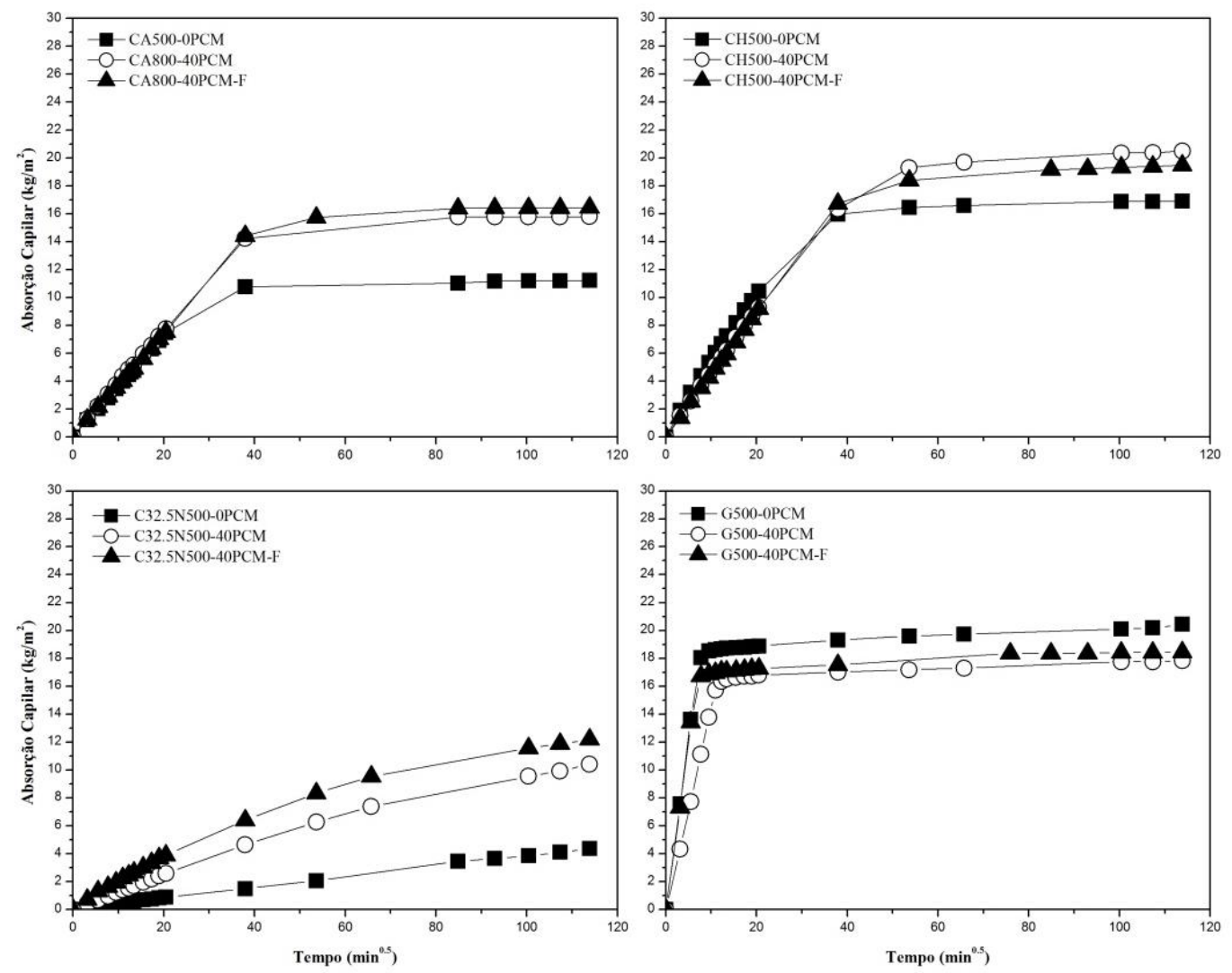

Figura 7: Evolução da absorção de água por capilaridade das argamassas desenvolvidas.

O coeficiente de absorção de água por capilaridade encontra-se relacionado com a velocidade de absorção de água, estando directamente relcionado com a presença de poros de menores dimensões. Tendo em conta os resultados de absorção capilar tudo indica que exista um aumento dos poros de menores dimensões quando se verifica um aumento no coeficiente de absorção capilar. Assim com, uma diminuição dos poros de pequenas dimensões quando se verifica um menor coeficiente de absorção capilar.

No que diz respeito à incorporação de $1 \%$ de fibras de poliamida e tendo em consideração que o seu objetivo principal foi controlar a retração em argamassas desenvolvidas, a sua presença originou uma diminuição no coeficiente de absorção capilar de cerca de 4\% nas argamassas de cal aérea, $13 \%$ nas argamassas à base de gesso e $63 \%$ em argamassas à base de cimento. As argamassas à base de cal hidráulica não apresentaram qualquer alteração. $\mathrm{O}$ que pode ser justificado pela conservação da razão água/ligante e também pelo fato destas fibras ocuparem total ou parcialmente alguns dos poros presentes na microestrutura das diferentes argamassas estudadas reduzindo assim, o efeito da presença de uma maior relação água/ligante nas argamassas com incorporação de PCM.

\subsection{Absorção de água por imersão}

A análise dos resultados obtidos (Figura 9) permite verificar que a incorporação de 40\% de PCM nas argamassas originou um aumento na absorção de água por imersão superior a 14\%. Contudo a incorporação de $1 \%$ de fibras permitiu originar uma diminuição na absorção de água superior a $8 \%$, com exceção das argamassas à base de cal hidráulica cujo valor não sofreu alteração. Foi também possível identificar que as argamassas à base de gesso e cal hidráulica são aquelas que possuem maiores valores de absorção de água por imersão. Por outro lado, as argamassas à base de cimento são as que possuem uma absorção de água por imersão inferior. 

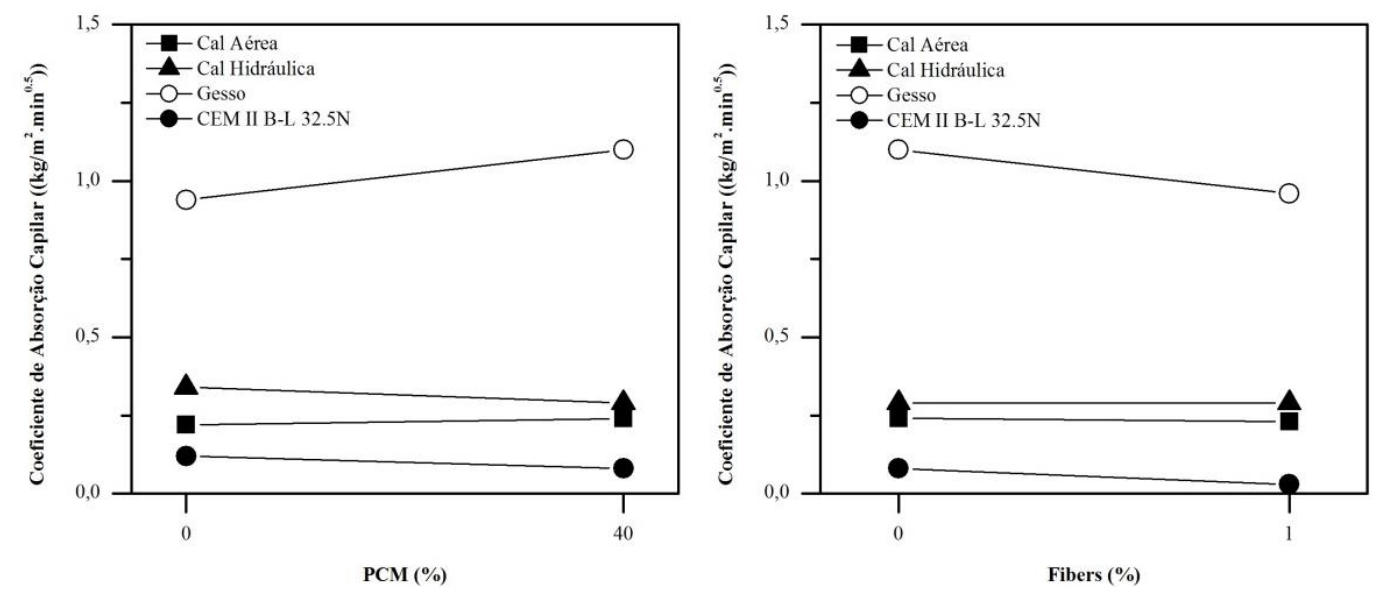

Figura 8: Coeficiente de absorção de água por capilaridade das argamassas desenvolvidas.
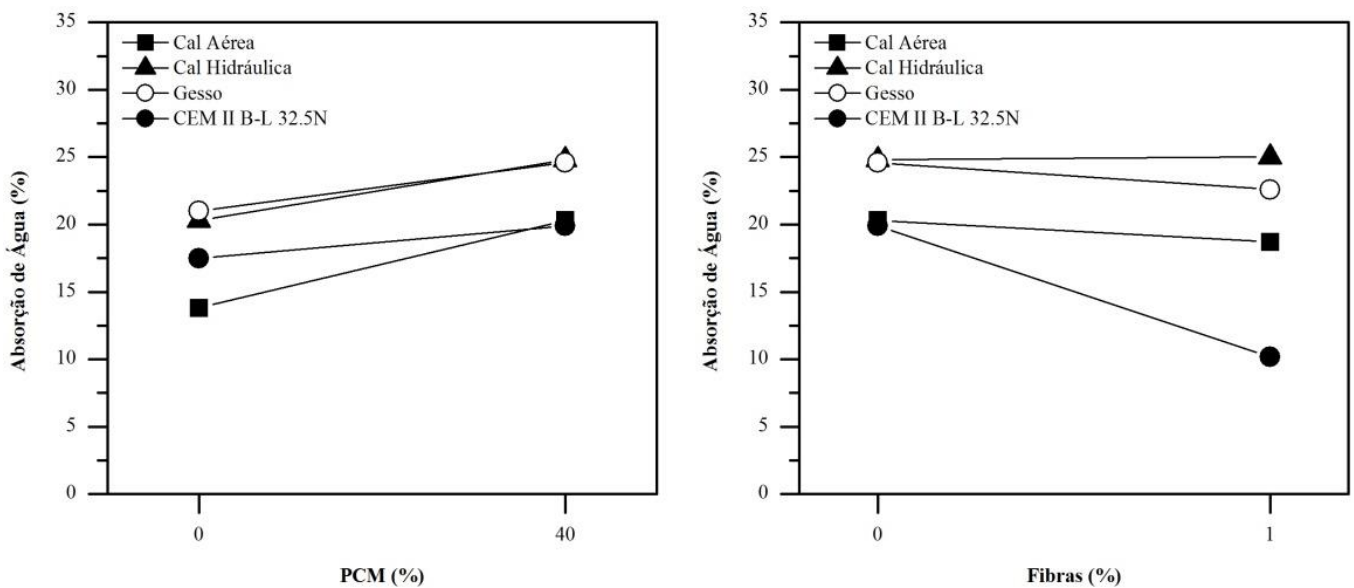

Figura 9: Abosrção de água por imersão das argamassas desenvolvidas.

\subsection{Gelo-degelo}

A durabilidade de uma argamassa aos ciclos gelo-degelo encontra-se relacionada com a sua capacidade para absorver a água, a velocidade com que a absorção de água é realizada e também com o fato de a argamassa possuir uma estrutura porosa e que seja capaz de resistir à tensão provocada pelo aumento de volume da água quando passa ao estado sólido. Assim, os ensaio cíclicos de gelo-degelo possuem um papel extremamente importante e decisivo na durabilidade das argamassas.

Estes testes consistem em submeter os elementos de ensaio a ciclos de temperaturas positivas e negativas. Sendo que, quando se verificam temperaturas negativas, a água que se encontra no interior da argamassa congela e consequentemente aumenta de volume ("gelo"). Se os poros das argamassas não se encontrarem saturados, os problemas que podem surgir são mínimos, uma vez que a água congelada é inferior ao volume dos poros. Contudo, no caso dos poros se encontrarem saturados, ou quase saturados, o aumento de volume resultante da congelação dá origem a pressões exercidas nas paredes dos poros ou seja na microestrutura das argamassas, podendo originar fissuração e até mesmo a destruição parcial do elemento em análise. No processo de descongelação ("degelo") a quantidade de água que anteriormente foi cristalizada retoma o seu volume inicial. No decorrer deste processo podem ocorrer duas situações distintas, sendo estas a secagem parcial ou total do elemento de ensaio devido à mudança de fase para o estado de vapor e a absorção de uma nova quantidade de água por capilaridade.

De acordo com a Figura 10, foi possível observar o comportamento das argamassas durante os ciclos de gelo-degelo. Em geral, pode observar-se que as argamassas à base de cimento são aqueles que apresentam uma maior resistência à ação de gelo-degelo, uma vez que não apresentam uma perda significativa de massa. Por outro lado, as argamassas mais sensíveis face a este tipo de agressão são as argamassas à base de cal aé- 
rea, que revelaram uma perda total dos elementos de ensaio em apenas alguns ciclos.
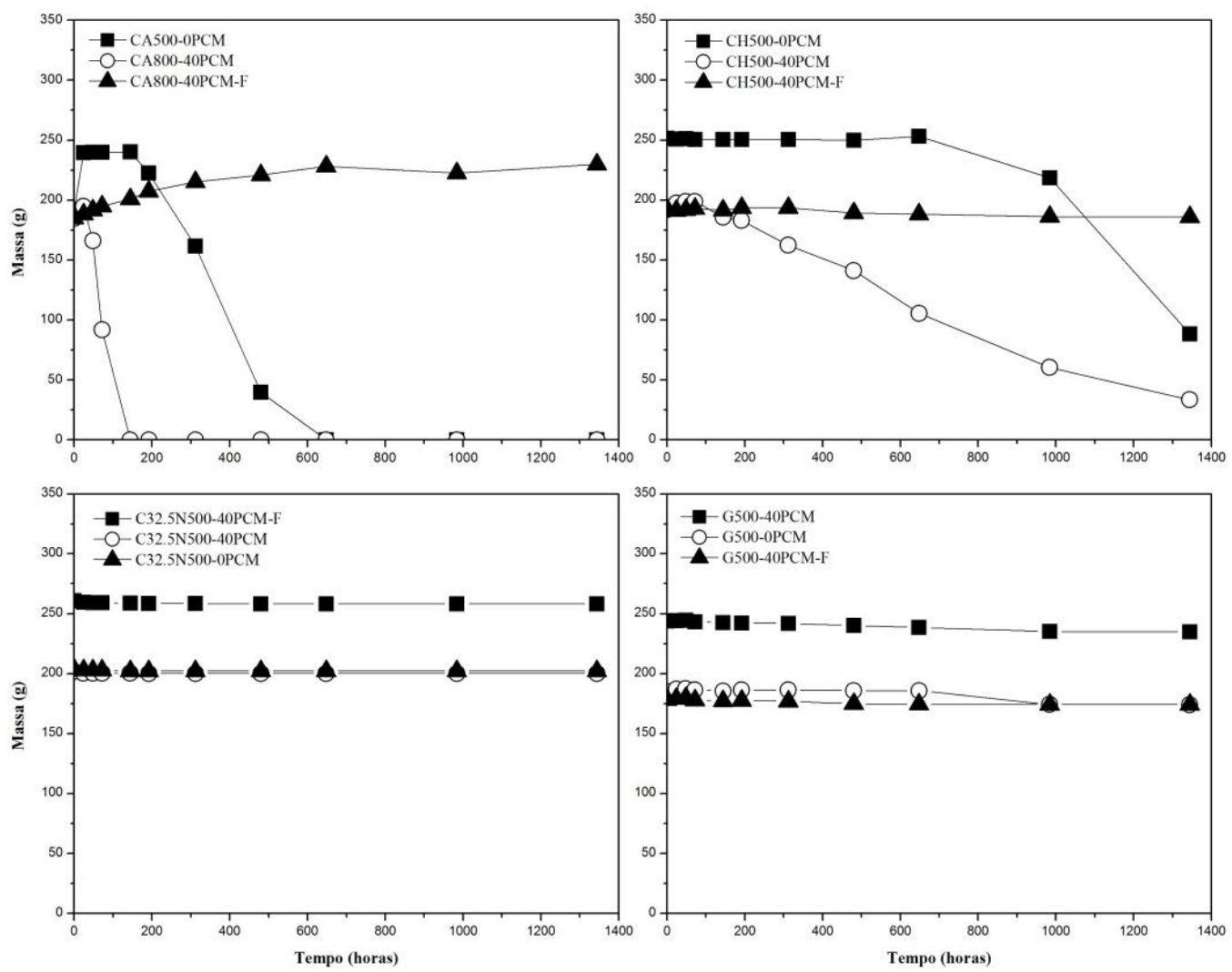

Figura 10: Perda de massa dos elementos de ensaio sujeitos ao teste de gelo-degelo.

A Tabela 4 apresenta a perda de massa, ou seja a degradação sofrida pelos elementos de ensaio das várias composições testadas durante a duração total dos testes gelo-degelo. Foi possível observar que a incorporação de material de mudança de fase, em geral conduziu a maiores perdas de material durante a ação do gelo-degelo, demostrando-se desta forma que a incorporação de PCM torna as argamassas mais susceptiveis de serem atacadas. Este comportamento encontra-se relacionado com a facilidade que os agentes agressores possuem em penetrar na argamassa e que pode ser comprovado pelo aumento da porosidade com a incorporação de PCM. Por outro lado, a incorporação de fibras e PCM permitiu em todas as argamassas testadas observar uma menor perda de massa, ou seja uma maior resistência à passagem dos agentes agressores, o que mais uma vez é comprovado pela diminuição da porosidade presente nas argamassas provocada pela introdução das fibras de poliamida.

Tabela 4: Perda de massa total no ensaio de gelo-degelo.

\begin{tabular}{l|l|l}
\hline COMPOSIÇÃo & LIGANTE & PERDA DE MASSA (\%) \\
\hline CA500-0PCM & Cal Aérea & 100 \\
\hline CA800-40PCM & Cal Aérea & 100 \\
\hline CA800-80PCM-F & Cal Aérea & 23,4 \\
\hline CH500-0PCM & Cal Hidráulica & 64,9 \\
\hline CH500-40PCM & Cal Hidráulica & 82,6 \\
\hline CH500-40PCM-F & Cal Hidráulica & 3,4 \\
\hline C500-0PCM & CEM II B-L 32.5N & 1,1 \\
\hline
\end{tabular}




\begin{tabular}{l|l|l}
\hline C500-40PCM & CEM II B-L 32.5N & 0,7 \\
\hline C500-40PCM-F & CEM II B-L 32.5N & 0,6 \\
\hline G500-0PCM & Gesso & 3,6 \\
\hline G500-40PCM & Gesso & 5,9 \\
\hline G500-40PCM-F & Gesso & 2,1 \\
\hline
\end{tabular}

\section{CONCLUSÃO}

A realização desta investigação permitiu concluir que a incorporação de material de mudança de fase em argamassas para revestimento no interior dos edifícios provoca alterações significativas nas suas propriedades no estado fresco e endurecido, assim como na sua durabilidade.

No que respeita à trabalhabilidade verificou-se que a incorporação de PCM provocou um aumento na quantidade de água necessária a adicionar à argamassa de forma a conferir uma trabalhabilidade adequada. Este aumento na razão água/ligante encontra-se relacionado com a finura característica do PCM, necessitando a argamassa de mais água de forma a obter uma pasta homogénea. Por outro lado, no estudo das resistências mecânicas (resistência à flexão, resistência à compressão e aderência) foi possível evidenciar uma diminuição das mesmas com a incorporação de PCM. Este fenómeno é uma consequência da presença de uma maior quantidade de água, sendo que origina uma maior porosidade nas argamassas, levando à diminuição da sua resistência mecânica.

A incorporação de material de mudança de fase afeta a durabilidade das argamassas desenvolvidas. Com base os ensaios de absorção de água por imersão foi possível observar que a incorporação de $40 \%$ de PCM, originou um incremento na porosidade das argamassas. Este aumento originou também uma maior sensibilidade de afetação no ensaio de gelo-degelo. Contudo, esta facilidade de penetração dos agentes agressores pode ser diminuída pela incorporação de $1 \%$ de fibras de poliamida. Este comportamento foi possível identificar com base nos resultados dos ensaios de absorção de água por imersão, tendo originado uma diminuição da porosidade presente nas argamassas e por consequência menores perdas de material quando os elementos foram sujeitos aos ensaios de gelo-degelo.

Relativamente aos ensaios de durabilidade foi ainda possível observar que as argamassas à base de cimento são aquelas que possuem uma menor sensibilidade às ações gelo-degelo e menor porosidade, tendo consequentemente um melhor comportamento. Por outro lado, as argamassas de cal aérea são aquelas cuja deterioração sofrida nos ensaio de gelo-degelo é superior, apresentando desta forma um comportamento mais sensível face aos agentes agressores.

Desta forma, é possível concluir que a incorporação de PCM nas argamassas de revestimento para o interior dos edificios pode ser realizada com sucesso. Por outro lado, as alterações verificadas nas argamassas podem ser contornadas através da incorporação de uma maior dosagem de ligante, superplastificante e até mesmo a inclusão de fibras para a solução de problemas relacionados com uma elevada retração. Todos estes procedimentos podem ser realizados dotando as argamassas de uma trabalhabilidade adequada à indústria da construção, assim como obtendo um aspeto final em tudo semelhante às argamassas tradicionais. É de notar que tendo em conta os ensaios realizados verificou-se que as argamassas à base de cimento são as que apresentam um melhor comportamento quando aditivadas com PCM. Por outro lado, as argamassas à base de cal aérea são as que apresentam uma maior sensibilidade à incorporação de microcápsulas de PCM. Contudo, importa referir que mesmo tendo-se verificado uma diminuição essencialmente das características mecânicas e durabilidade das argamassas desenvolvidas com incorporação de PCM, todas apresentam pelo menos os requisitos mínimos para que possam ser aplicadas.

Desta forma é possível concluir que a entrada no mercado deste tipo de argamassas de reboco para o interior dos edifícios será bem recebida pelos profissionais da área e também pelos utilizadores, uma vez que é possível obter uma solução construtiva funcional e com grande capacidade de adaptação aos edifícios novos e também em operações de reabilitação. Contudo, importa referir que os resultados promissores deste trabalho indicam também uma necessidade de continuidade de investigação nesta área, uma vez que este trabalho assinala os primeiros passos da comparação de diferentes argamassas com incorporação de PCM.

\section{AGRADECIMENTOS}

Os autores desejam expressar os seus agradecimentos à Fundação para a Ciência e Tecnologia pelo financiamento deste trabalho de investigação desenvolvido no âmbito do projeto "Contribuição de Argamassas Tér- 
micas Ativas para a Eficiência Energética dos Edifícios" (PTDC/ECM/102154/2008) e à atribuição da bolsa individual de doutoramento com referência SFRH/BD/95611/2013.

\section{BIBLIOGRAFIA}

[1] DIAMANTI, M., ORMELLESE, M., PEDEFERRI, M., "Characterization of photocatalytic and superhydrophilic properties of mortars containing titanium dioxide", Cement and Concrete Research, v. 38, pp. 1349-1353, Nov. 2008.

[2] CAMÕES, A., Betões de elevado desempenho com incorporação de cinzas volantes, Tese de D.Sc., Universidade do Minho, Guimarães, Portugal, 2002.

[3] SOARES, N., COSTA, J., GASPAR, A., et al., "Review of passive PCM latent heat thermal energy storage systems towards buildings energy efficiency", Energy and Buildings, v. 59, pp. 82-103, Apr. 2013.

[4] BLENGINI, G., CARLO, T., "The changing role of life cycle phases, subsystems and materials in the LCA of low energy buildings", Energy and Buildings, v. 42, pp. 869-880, Jun. 2010.

[5] CABEZA, L., CASTELL, A., BARRENECHE, C., et al., "Materials used as PCM in thermal energy storage in buildings: A review", Renewable and Sustainable Energy Reviews, v. 15, pp. 1675-1695, Apr. 2011.

[6] CARDOSO, I., Aplicação de Microcápsulas de PCM em Materiais de Isolamento Térmico para Fatos de Protecção e Combate ao Fogo, Universidade do Minho, Guimarães, Portugal, 2006.

[7] TYAGI, V., KAUSHIK, S., TYAGI, S., et al.,"Development of phase change materials based microencapsulated technology for buildings: A review", Renewable and Sustainable Energy Reviews, v. 15, pp. 1373-1391, Feb. 2011.

[8] SILVA, N., Incorporação de Materiais de Mudança de Fase em Materiais de Construção, Universidade do Minho, Guimarães, Portugal, 2009.

[9] PCM ENERGY, http://www.teappcm.com/. Acessado em maio de 2013.

[10] SHARMA A., TYAGI, V., CHEN, C., et al., "Review on thermal energy storage with phase change materials and applications", Renewable and Sustainable Energy Reviews, v. 13, pp. 318-345, Feb. 2009.

[11] ATHIENITIS, A., LIU, C., HAWES, D., et al., "Investigation of the Thermal Performance of a Passive Solar Test-Room with Wall Latent Heat Storage", Building and Environment, v. 32, pp. 405-410, Sep. 1997.

[12] SHILEI, L., NENG, Z., GUOHUI, F., "Impact of Phase Change Wall Room on Indoor Thermal Environment in winter", Energy and Buildings, v. 38, pp. 18-24, Jan. 2006.

[13] AHMAD, M., BONTEMPS, A., SALLÉE, H., et al., "Thermal Testing and Numerical Simulation of a Prototype Cell Using Light Wallboards Coupling Vacuum Isolation Panels and Phase Change Material", Energy and Buildings, v. 38, pp. 673-681, Jun. 2006.

[14] NAGANO, K., TAKEDA, S., MOCHIDA, T., et al., "Study of a Floor Supply Air Conditioning System Using Granular Phase Change Material to Augment Building Thermal Mass Storage - Heat Response in Small Scale Experiments", Energy and Buildings, v. 38, pp. 436-446, May. 2006.

[15] LIN, K., ZHANG, Y., XU, X., DI, H., YANG, R., QIN, P., "Experimental Study of Under-Floor Electric Heating System with Shape-Stabilized PCM Plates", Energy and Buildings, v. 37, pp. 215-220, Mar. 2005.

[16] GRIFFITHS, P., EAMES, P., "Performance of chilled ceiling panels using phase change material slurries as the heat transport medium", Applied Thermal Engineering, v. 27, pp. 1756-1760, Jul. 2007.

[17] ISMAIL, K., HENRIQUEZ, J., "Thermally Effective Windows with Moving Phase Change Materials Curtains", Applied Thermal Engineering, v. 21, pp. 1909-1923, Dec. 2001.

[18] ENTROP, A., BROUWERS, H., REINDERS, A., "Experimental research on the use of microencapsulated Phase Change Materials to store solar energy in concrete floors and to save energy in Dutch houses", Solar Energy, v. 85, pp. 1007-1020, May. 2011.

[19] CUNHA, S., ALVES, V., AGUIAR, J., et al., "Use of phase change materials microcapsules in aerial lime and gypsum mortars", Cement Wapno Beton, Special Issue, pp. 17-21, 2012.

[20] CUNHA, S., AGUIAR, J., KHERADMAND, M., et al., "Thermal mortars with incorporation of PCM microcapsules", Restoration of Buildings and Monuments, v. 19, pp. 171-177, Mar. 2013. 
[21] CUNHA, S., AGUIAR, J., FERREIRA, V., et al., "Influence of Adding Encapsulated Phase Change Materials in Aerial Lime based Mortars", Advanced Materials Research, v. 687, pp. 255-261, Apr. 2013.

[22] EUROPEAN COMMITTEE FOR STANDARDIZATION (CEN), EN 1015-11, "Methods of test for masonry - Part 11: Determination of flexural and compressive strength of hardened mortar", 1999.

[23] EUROPEAN COMMITTEE FOR STANDARDIZATION (CEN), EN 1015-12, "Methods of test for mortar for masonry - Part 12: Determination of adhesive strength of hardened rendering and plastering mortars on substrates", 2000.

[24] EUROPEAN COMMITTEE FOR STANDARDIZATION (CEN), EN 1015-18, "Methods of test for masonry - Part 18: Determination of water absorption coefficient due to capillary action of hardened mortar", 2002.

[25] LABORATÓRIO NACIONAL DE ENGENHARIA CIVIL (LNEC), Especificação E 394, "Betões Determinação da absorção de água por imersão", 1993.

[26] EUROPEAN COMMITTEE FOR STANDARDIZATION (CEN), CEN/TS 12390-9, “Testing hardened concrete - Part 9: Freeze-thaw resistance", 2006.

[27] EUROPEAN COMMITTEE FOR STANDARDIZATION (CEN), EN 1015-3, "Methods of test for mortar for masonry - Part 3: Determination of consistence of fresh mortar (by flow table)", 1999.

[28] INSTITUTO PORTUGUÊS DA QUALIDADE (IPQ), NP EN 998-1, "Especificações de argamassas para alvenarias - Parte 1: Argamassas para rebocos interiores e exteriores", 2010. 